\title{
A RETURN TO THE "RULES OF THUMB" IN MARITIME ENGINEERING FOR DIGITAL NATIVE STUDENTS
}

\author{
Gabriel Chamorro', Pablo Cabrera², Juan J. Muñoz-Perez ${ }^{2}$ \\ ${ }^{1}$ Dept. of Civil Engineering. Engineering Superior School. University of Seville (SPAIN) \\ ${ }^{2}$ Coastal Engineering Research Group, University of Cadiz (SPAIN)
}

\begin{abstract}
Engineering and technical degrees are difficult to teach and, consequently, have always been characterized by a large number of academic failures. That is the reason why different methodologies have been applied to classes of similar content in different countries [1]. Among these methodologies, it is noteworthy to mention audio/visual resources as a useful tool to improve the teaching of coastal engineering [2], which means more students that pass the coastal engineering courses [3]. Moreover, use of GPS and Google Earth have also shown to be useful tools to improve the learning process [4]. Nevertheless, the authors have not found anything about the use of "rules of thumb" as a better way for students to improve their comprehension of the basic knowledge of an engineering subject.
\end{abstract}

This paper shows the teaching experience on Maritime Engineering for undergraduate students of Civil Engineering in the School of Engineering at the University of Seville (Spain). The application of new information technologies in classrooms and advanced training in the use of finite element software tools and programming languages gives our students extremely powerful tools for solving very complex engineering problems with excellent results.

However, the enormous effort invested by the students in acquiring this advanced knowledge and to be up to date in using and commanding on these technologies leads them to focus their main efforts, attention and skills just toward the numerical resolution of the problem, the efficiency of the implemented algorithm, and the programming language difficulties. This puts aside the essential and the critical sense of the accuracy of the results obtained by the algorithm. The students do not get the physical 'feeling' of what's happening in the algorithm.

We have included a teaching sequence in our lesson programs that always starts with an historical review of the different approaches used by engineers in their times in order to solve engineering problems from the seventeenth through the nineteenth century to today. This method makes the students to appreciate the importance and wits required by those men in the past in facing a difficult task when they didn't have a PC or powerful software.

The "rules of thumb" in engineering become a powerful tool for the digital native students which helps them make sense and enjoy the study and programming when they finally find out that their algorithm responds with reasonable accuracy and orders of magnitude to the result expected beforehand. Simply applying "rules of thumb" and well-known approximations of the past, perhaps obsolete from a technical point of view, will help the student learn the process.

Some examples will be given in this paper in order to show the use of these "rules of thumb" or simplified models in class for teaching Maritime Engineering subject. Among them: the dimensionless stability number of Vicente Negro [5] for the design of the armour layer blocks in breakwaters, the Iribarren's wave drawings [6], the US Army Corps of Engineers Shore Protection Manual Graphs and plates, etc.

Keywords: rules of thumb, innovation, coastal engineering teaching, digital native.

\section{INTRODUCTION}

As Civil Engineering students in the 90's we shyly began to use numerical models like the finite element method (FEM) and to program codes using FORTRAN in workshops. Even so we cannot be regarded as 'digital natives' at all.

In fact, engineers of that generation and before have had to develop considerable effort in updating with those new technologies in order to perform efficiently their daily technical activity in a world where a massive use of software and powerful mathematical models are required in design. Undoubtedly those tools are essential nowadays. 
The 'Rules of Thumbs' (ROT) in ocean engineering practice used by the old engineers (and some not so old) have led to the design of major Spanish ports that we still have in exploitation today. This is a remarkable idea in the present article. Those infrastructures have shown excellent performance after the constant attack of Cantabrian Sea storms during the last 50 years. Nevertheless it is unthinkable today to face a port design without the intensive use of advanced models which lets us to substantially increase safety and reduce costs.

The key problem in using these powerful and 'friendly' tools appear when the young user hasn't inculcated the physical sense of coastal and wave propagation phenomena. As a result, the inexperienced user blindly believes the colourful and astonishing colormap output generated by an upto-date FEM model.
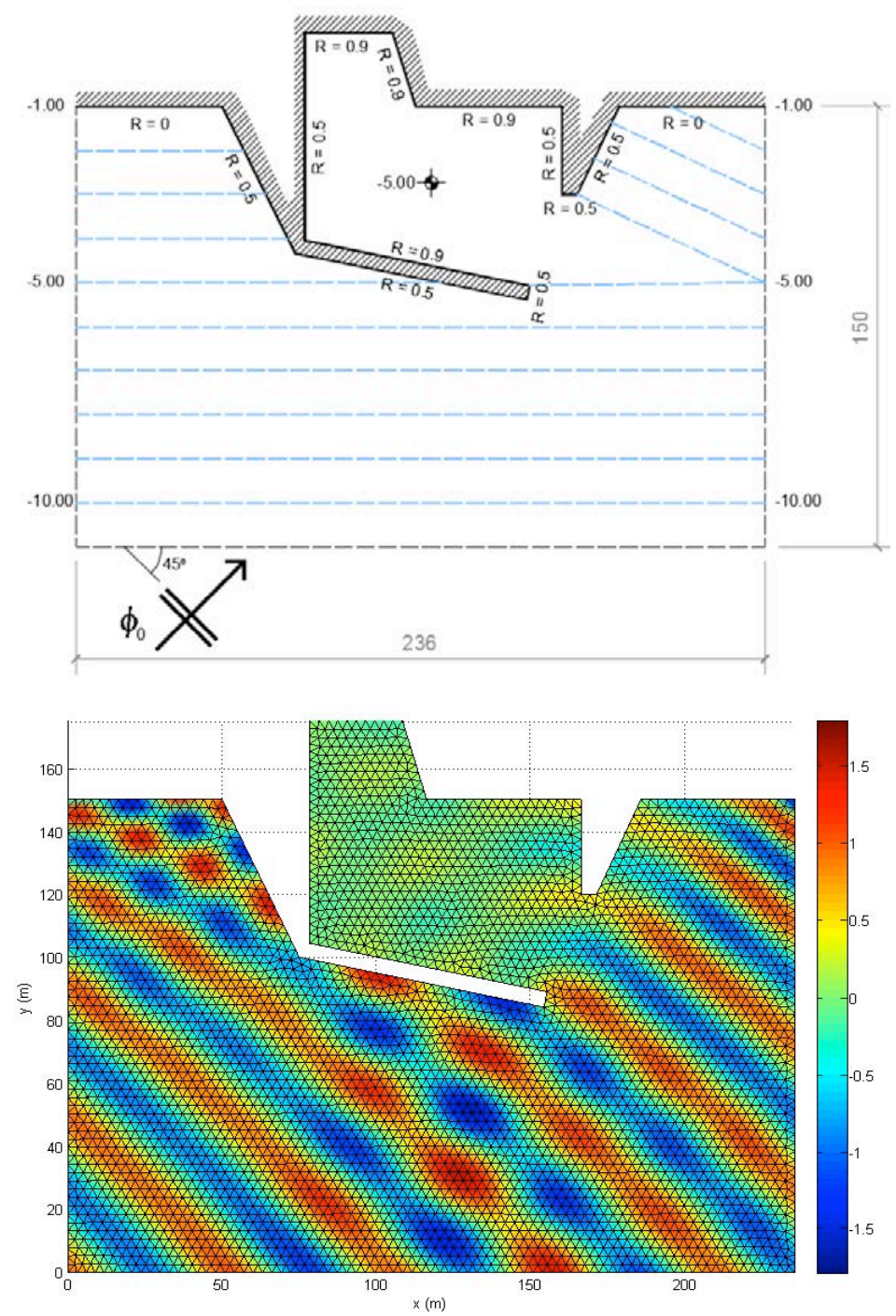

Fig. 1. Example of a Mild-Slope equation FEM numerical model.

Undoubtedly the knowledge and use of numerical methods as the FEM is essential for the professional development of the $21^{\text {th }}$ century engineers, but its use without a minimum common sense or the physical intuition, even roughly, of the expected result may become hazardous, mainly for young and inexperienced engineers.

\section{A BIT OF HISTORY AND RULES OF THUMB}

It hasn't been that long since the ocean engineers, as the great Ramon Iribarren (before the 60's) had no choice but to face complex maritime engineering problems with much ingenuity, intuition and ROT. As a delicious example of this we would like to mention the Iribarren's wave drawings that allow us to 
obtain the propagation coefficients and deformation of the wave fronts with uneven bathymetry, employing a graphical method that merits the qualification of a masterpiece and legacy of the Spanish Civil Engineering.
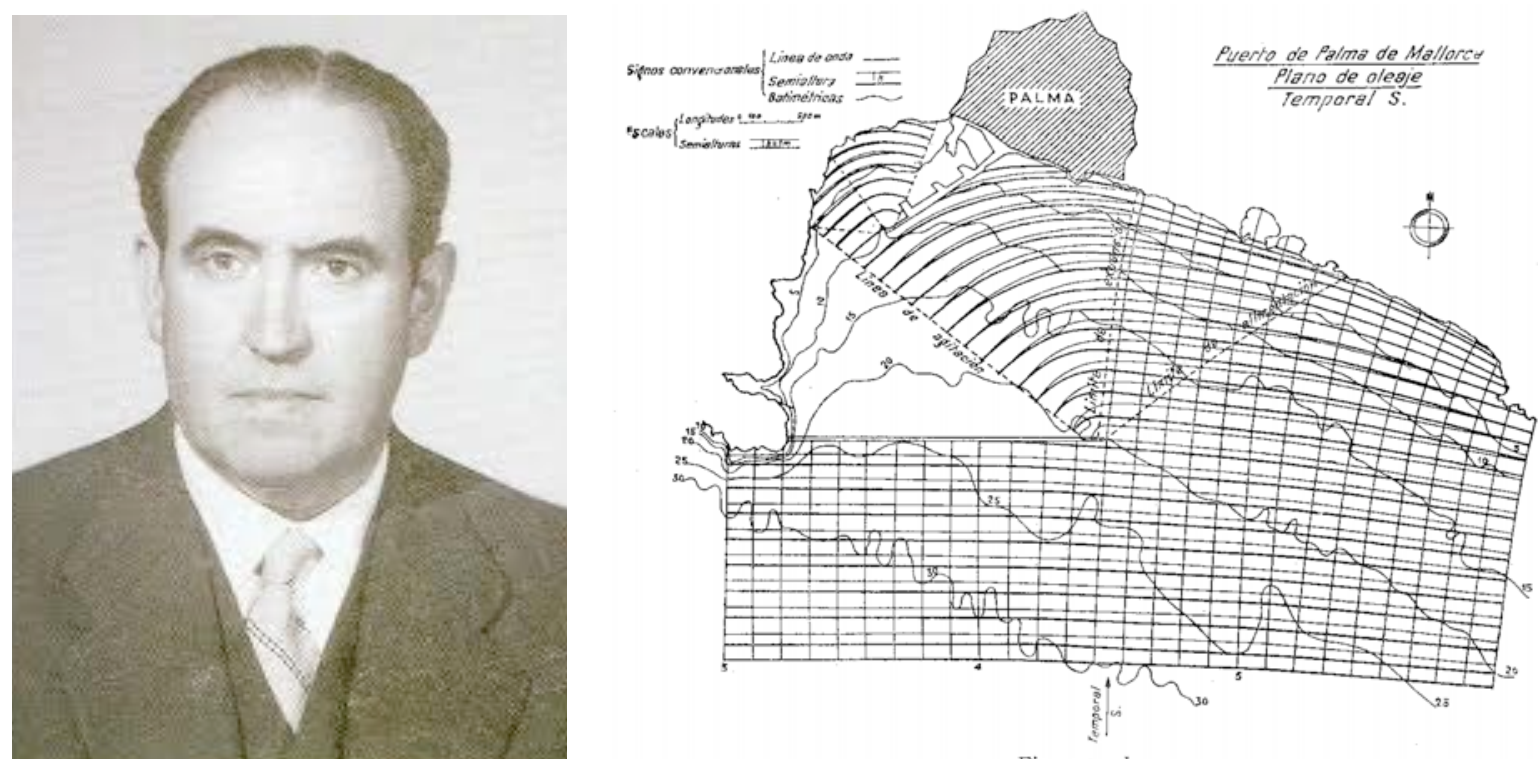

Fig. 2. Prof. Ramón Iribarren Cabanilles (1900 - 1967). Wave propagation drawing of the Palma de Mallorca Port. Balearic Islands (Spain).

Occasionally we have had encounters and discussions with some colleagues and professors that teach maritime engineering subject in other universities around Spain. In discussing the importance or not of including these 'old-fashion matters' in our course programs we have found a considerable disagreement.

There are those who quote those methods of other times as obsolete matter, and we agree with them only from a professional point of view nowadays. Obviously nobody uses these techniques in design today. However we still haven't found a better and clearer way to teach our students the physics behind the processes of wave propagation in shallow waters. The results obtained have been excellent when the students were asked to perform a wave drawing by themselves. The process of drawing is tedious but straightforward and we have observed that the student really enjoys the task.

But the main success of all is that the students from that moment on are able to sketch a propagating wave front, with reasonable precision, just using their intuition and observing a bottom bathymetry.

Mission accomplished! After this training process the student is ready to understand and discuss the results of mathematical models like the Mild-Slope Equation.

\subsection{Our best friend Mr straight-and-parallel-depth-contours}

The study of the wave propagation phenomena over uneven bottoms must start with the simplified straight and parallel deep contours theoretical model. First of all because it is a very simple and easy to understand model and, second because we have verified in class that going straight to the general case of uneven bottom is educationally counterproductive.

When the students acquires the basic intuition of wave propagation phenomena using the simplified model it is easier for them to extrapolate to any kind of bathymetry, even if it is a very complex one.

Even today practicing engineers use those simplified models in order to get a rough figure of the propagation (shoaling and refraction) coefficients for a preliminary design of maritime structures. A good rough figure obtained from a rule of thumb is an excellent method to calibrate the numerical model results.

As a classical example, the USACE 1984 Shore Protection Manual (SPM) plate for the shoalingrefraction coefficient with straight, parallel deep contours is shown below. This plate has been extensively used by civil engineer all around the world for the design or maritime structures in the middle of the 20th century. Even today it is an excellent tool for preliminary design. Knowing the period 
and the wave front angle with respect to the deep contours in deep water it is straightforward to get the shoaling-refraction coefficient and the deformed wave front angle at any depth during propagation.

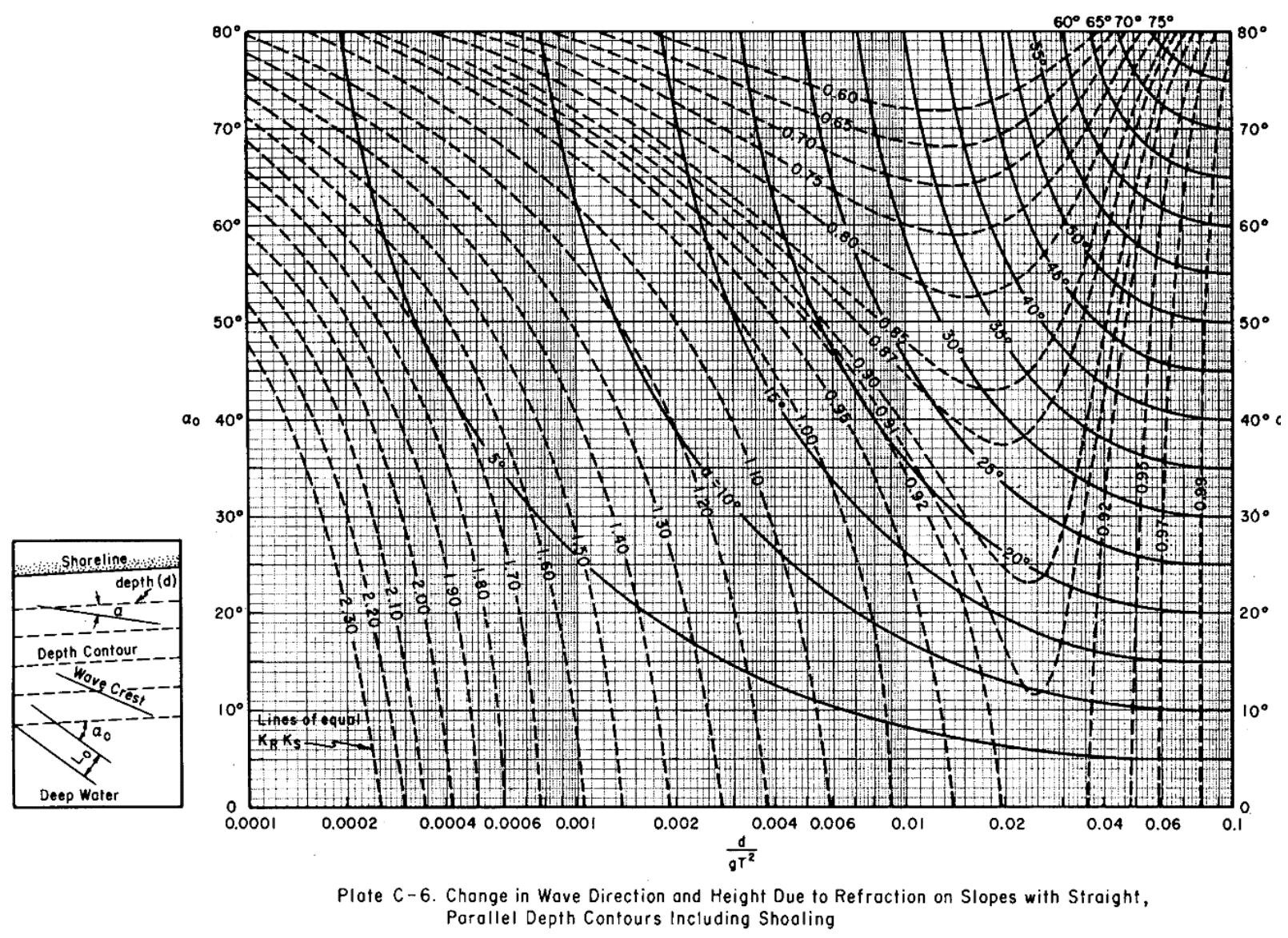

Fig. 3. Shoaling-Refraction coefficient. USACE 1984 Shore Protection Manual (SPM) with straight, parallel depth contours.

\subsection{Simplified models for diffraction with constant depth}

Up to now we have only treated issues related to the shoaling and refraction phenomena. Diffraction is another essential phenomenon to be considered in port and coastal design.

The mathematical approach to the diffraction phenomena is overwhelming for our students. Even the analytical solutions for the case of constant depth, like the Penny and Price or Wiegel methods, is cumbersome and it means an expense of hours that we usually can hardly afford in our limited teaching schedules. In an initial stage we prefer to focus energy on the physics behind the diffraction phenomena, leaving for a later stage the mathematical stuff.

The dimensionless Wiegel charts in the USACE SPM (1984), for semi-infinite rigid impermeable breakwater, are an excellent introduction to explain the lateral energy transfer during diffraction behind a natural or artificial obstacle during propagation. Although we have avoided the mathematical background at the beginning we get a better goal, i.e. the student acquires the intuition and in a natural way discovers that the propagation coefficient within the shadow area behind the obstacle becomes automatically less than one half. This conclusion is not so obvious! 


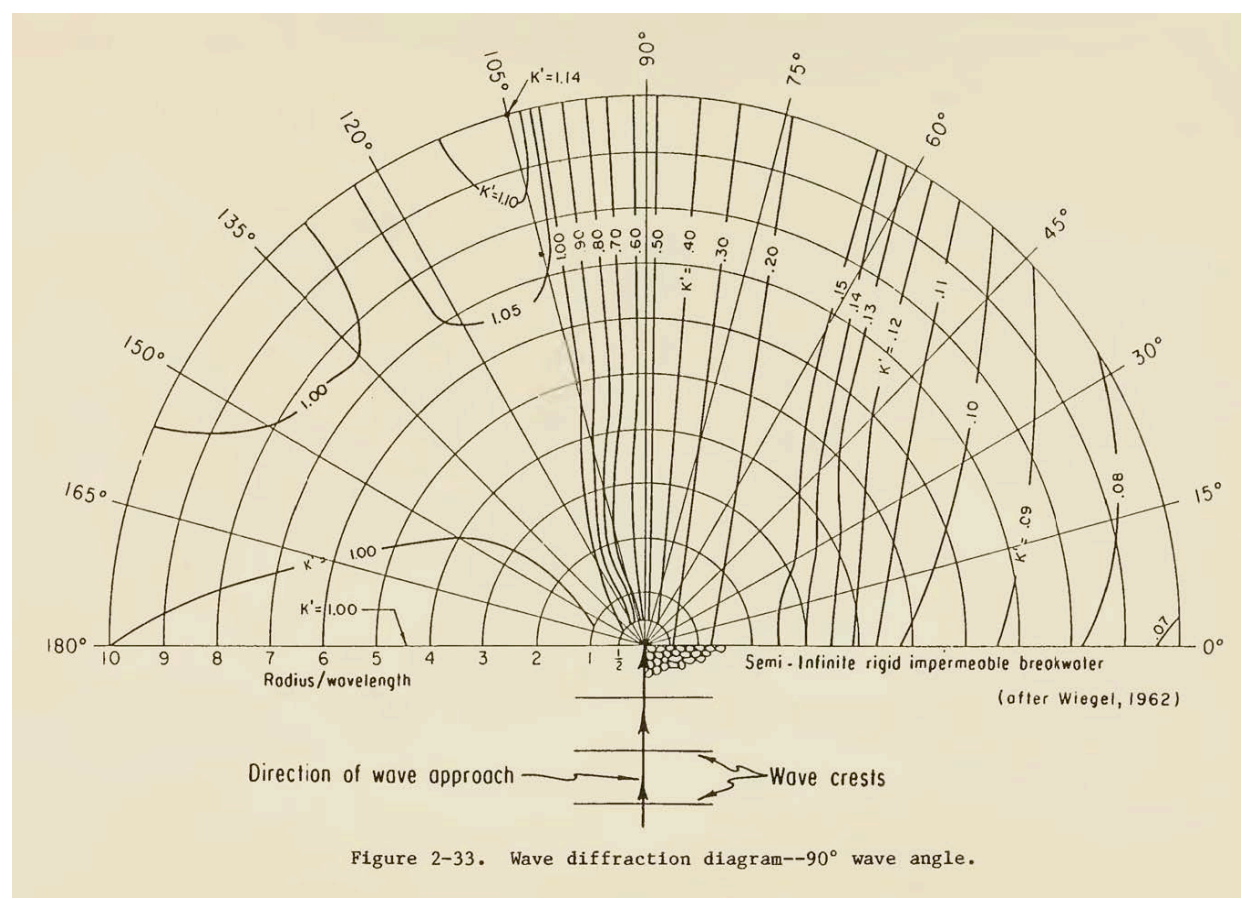

Fig. 4. Dimensionless Weigel diffraction plate. USACE SPM (1984)

Every year some students ask the same question. What happens if the depth behind the breakwater is not constant? This is a natural question. We insist in class in the fact that this model is not accurate in that case, but even so it is a good approximation for the exact solution from an engineering point of view. In most cases port basins are dredged in order to get a constant basin depth compatible with navigation. For this reason this simple diffraction model has not ceased to be valid for engineering practice.

Only wise men are able to make simple the difficult things. In our classes about diffraction we always tell the elegant explanation about diffraction of Professor Baker in his classes in the MSc in Ocean Engineering at the University of Hawaii (personal reference from Prof. Gómez-Pina). This physical explanation is so simple, elegant, plain, and pedagogical that the authors of this paper consider it as an essential reference in teaching the wave propagation phenomena for undergraduate students.

Observe in the figure below how the presence of an obstacle, such as a breakwater, is responsible for the disappearance of the emission of one 'ray' from point P', thereby causing the wave height in line $\mathrm{M}-\mathrm{M}$ to be just half of the incident wave. That's great!

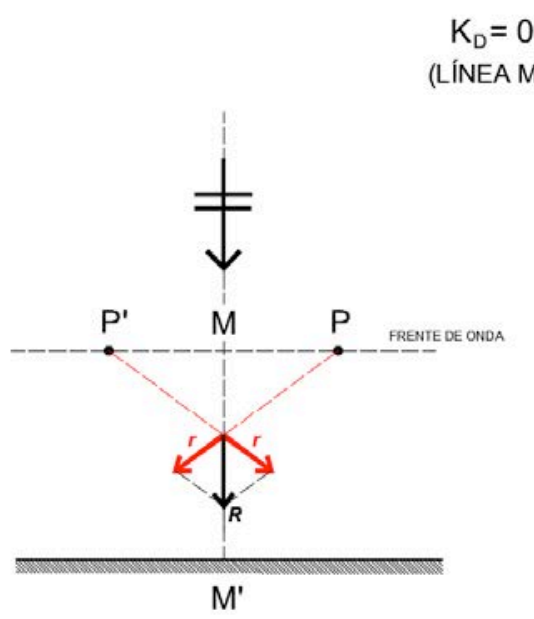

SIN OBSTÁCULO

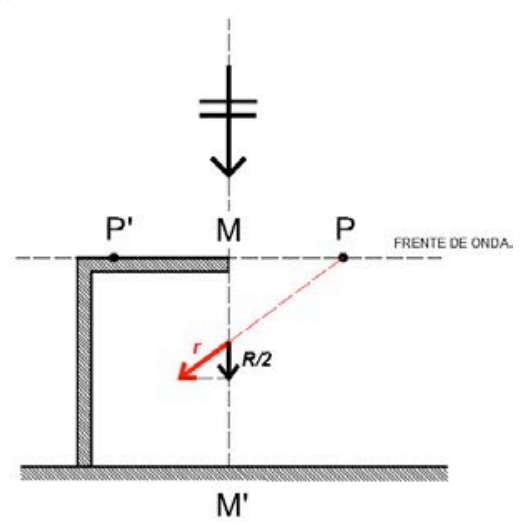

CON OBSTÁCULO

Fig. 5. Professor Baker's explanation of diffraction phenomena. 
As a final remark to this short historical review, we conclude that the use of these simplified models or rules of thumbs in engineering are still a good approximation for preliminary design. It is obvious though that better, more accurate and safer results can be obtained from the cautious use of advanced mathematical models. Nevertheless, experience, knowledge and common sense are indispensably required.

\section{THE BASIC EXERCISE TO EVALUATE THE STUDENT'S SKILLS}

In this section we'll show a basic example of exam exercise that will let the professor know accurately if the students have learnt the basis of the subject. This is in fact a very simple but complete task that reviews all the necessary background and knowledge needed by the undergraduate student to succeed in the subject. It covers the matter from the linear theory of waves to the propagation phenomena, which takes about two months of classes in our teaching schedule.

The whole exercise can be done using the rules of thumbs outlined above. In our humble opinion any civil engineer engaged in wave modelling should know how to solve this task unhesitatingly since these results are essential to calibrate the model.

Let's imagine that we are concerned with a port preliminary design located on the west coast of Andalusia (Cadiz Gulf), southern Spain. We assume that the shoreline alignment is east-west. The bathymetry is straight, parallel to the shoreline alignment, as shown below in Fig. 6 .

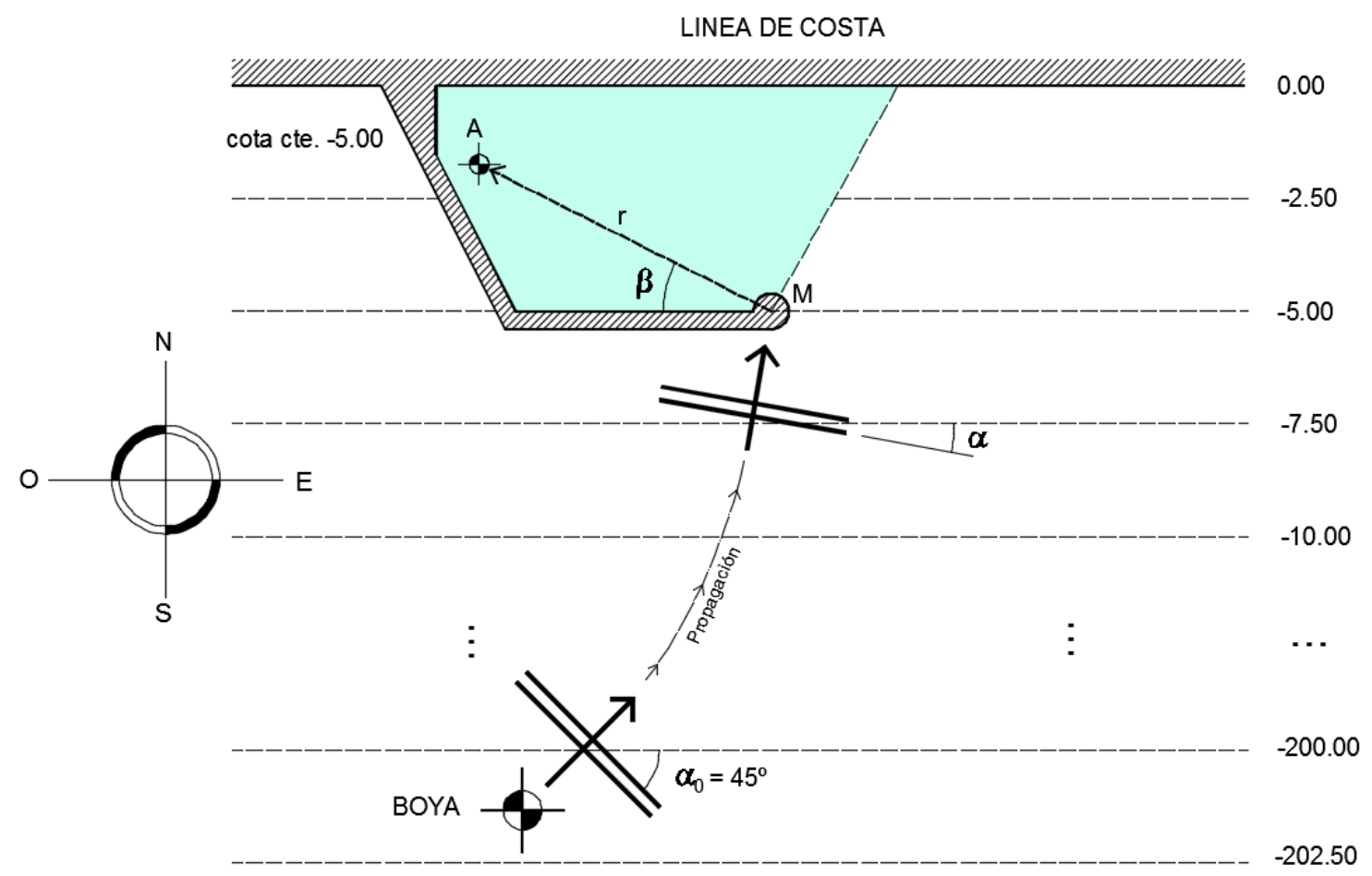

Fig. 6. Basic outline of the problem.

The ocean data used in this exercise have been obtained from the Spanish Port Authority (www.puertos.com), which has a directional wave measuring buoy anchored in some position in the Cadiz Gulf at $400 \mathrm{~m}$ depth (deep water).

The design storm parameters are characterized by a significant wave height $\mathrm{H}_{0}=5.00 \mathrm{~m}$, a period of 10 seconds and approach direction of wave fronts from the southwest.

The maximum or spring tidal range at the design area is $3.75 \mathrm{~m}$ and it has been measured by a tide gage located inside the Huelva City Harbour. The depth at point M (breakwater tip) is $-5.00 \mathrm{~m}$ referred to the Lowest Low Water Level (LLWL) Datum. The harbour basing has constant depth because it will be dredged at $-5.00 \mathrm{~m}$, referred also to the LLWL. 
Point $A$ is located $250 \mathrm{~m}$ away from point $M$ at an angle of $30^{\circ}$ referred to the breakwater alignment.

The student must obtain an estimate of the propagated wave height at point $A$ located within the harbour basin, in the worst possible situation of water level.

\section{Exercise solution:}

Obviously the worst possible water level situation in order to obtain the maximum wave height at point A occurs when water depth is a maximum, i.e. when the maximum possible tidal level occurs. The reason for this is that at the maximum level a higher wave can enter the harbour basin without breaking. As a good rule of thumb of the breaking index $(\mathrm{H} / \mathrm{d})$ we can use the McCowan criterion (1891): $\mathrm{H} / \mathrm{d}=0.78$, where $\mathrm{H}$ is the wave height and $\mathrm{d}$ is water depth.

First of all, we need the wave parameters at deep water where the buoy is located. Knowing that the period $T$ keeps constant during propagation, we can calculate the wavelength $L_{0}$ in deep water from the linear theory dispersion equation:

$\mathrm{L}_{0}=\mathrm{gT}^{2} / 2 \pi=156 \mathrm{~m}$

Once we have got $L_{0}$ it is straightforward to obtain the wavelength at point $M$. Attention! Water depth at point $M$ must be increased by the tidal range, i.e. $h_{M}=5.00+3.75=8.75 \mathrm{~m}$. Now we use again the dispersion equation, but in this case in its general expression for intermediate water depth:

$\mathrm{L}=\left(\mathrm{gT}^{2} / 2 \pi\right) \cdot \tanh (\mathrm{kh})=\mathrm{L}_{0} \cdot \tanh (\mathrm{kh})$

This is an implicit equation which has to be solved by iteration, knowing depth at point $\mathrm{M}$ and period. A classical way to solve this small inconvenience is by using the USACE SPM Wave charts which prevent us to do the tedious iteration process every time (see also e.g. [7]).

\begin{tabular}{|c|c|c|c|c|c|c|c|c|c|c|c|c|c|}
\hline$d / L_{0}$ & $d / L$ & $2 \pi \mathrm{d} / \mathrm{L}$ & $\begin{array}{l}\text { TANH } \\
2 \pi d\end{array}$ & $\begin{array}{l}\text { SIN } \\
2 \pi\end{array}$ & $\begin{array}{l}\operatorname{Cosh} \\
2 \pi d / 1\end{array}$ & $\mathrm{H} / \mathrm{H}^{\prime}$ & $\mathrm{K}$ & $4 \pi d /$ & $\begin{array}{l}\text { SLNH } \\
4 \pi \cdot d / L\end{array}$ & & $n$ & & $M$ \\
\hline $\begin{array}{l}05100 \\
05200 \\
05300\end{array}$ & $\begin{array}{l}.09520 \\
.09623 \\
.09726 \\
.09829\end{array}$ & $\begin{array}{l}.5916 \\
.5981 \\
.6046 \\
.6111\end{array}$ & $\begin{array}{l}.5310 \\
.5357 \\
.5403 \\
.5449 \\
.5494\end{array}$ & $\begin{array}{l}.6267 \\
.6344 \\
.6421 \\
.6499\end{array}$ & & $\begin{array}{l}1.023 \\
1.019 \\
1.016 \\
1.013 \\
1.010\end{array}$ & $\begin{array}{l}.8473 \\
.84444 \\
.8415 \\
.8385 \\
.8356\end{array}$ & $\begin{array}{l}1.183 \\
1.196 \\
1.209 \\
1.222\end{array}$ & $\begin{array}{l}1.479 \\
1.503 \\
1.526\end{array}$ & & & $\begin{array}{l}.4779 \\
.4811 \\
.4842 \\
.4873 \\
.4903\end{array}$ & \\
\hline $\begin{array}{l}.05500 \\
.05600 \\
.05700\end{array}$ & $\begin{array}{l}.09930 \\
.1003 \\
.1013 \\
.1023\end{array}$ & $\begin{array}{l}.6239 \\
.6303 \\
.6366 \\
.6428 \\
.6491\end{array}$ & $\begin{array}{r}.5538 \\
.5582 \\
.5626\end{array}$ & $\begin{array}{l}.6729 \\
.6805\end{array}$ & $\begin{array}{l}1.2053 \\
1.2096 \\
1.2138 \\
1.2181\end{array}$ & $\begin{array}{l}1.007 \\
1.004 \\
1.001 \\
.9985 \\
.9958\end{array}$ & $\begin{array}{l}.8326 \\
.8297 \\
.8267 \\
.8239 \\
.8209\end{array}$ & $\begin{array}{l}1.248 \\
1.261 \\
1.273 \\
1.286 \\
1.298\end{array}$ & & $\begin{array}{l}5 \\
6 \\
6 \\
7 \\
8\end{array}$ & $\begin{array}{l}.8905 \\
.8886 \\
.8867 \\
.8849 \\
.8830\end{array}$ & $\begin{array}{l}.4932 \\
.4960 \\
.4988 \\
.5015 \\
.5042\end{array}$ & $\begin{array}{l}16.09 \\
15.84 \\
15.60 \\
15.36 \\
15.13\end{array}$ \\
\hline
\end{tabular}

Fig. 7. USACE SPM wave calculation chart.

In this case $d / L_{0}=0.0548$, thus searching the interpolated value $d / L$ in the above chart, we obtain:

$\mathrm{d} / \mathrm{L}_{0}=0.0548 \rightarrow \mathrm{d} / \mathrm{L}=0.09879 \rightarrow \mathrm{L}_{\mathrm{M}}=88 \mathrm{~m}$.

It is noteworthy that the wavelength decreases when the wave front propagates towards the shoreline.

Now we will calculate the propagation coefficient and wave front angle to point M. Only shoaling and refraction phenomena occur from deep water (buoy) to point M. Using the USACE SPM shoalingrefraction chart shown above:

$\mathrm{d} / \mathrm{gT}^{2}=0,009 ; \mathrm{a}_{0}=45^{\circ}$ 


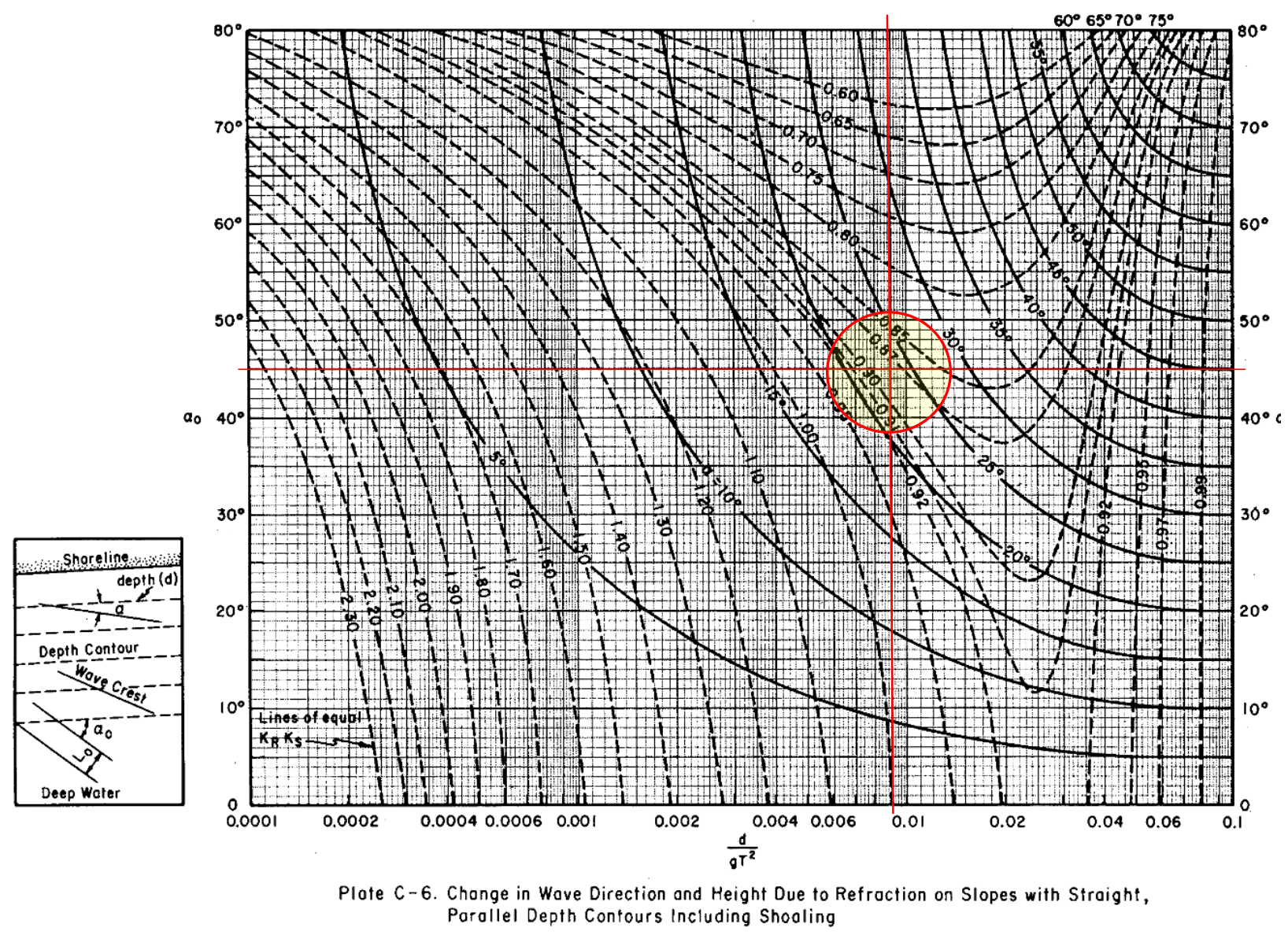

Fig. 8. Shoaling-Refraction coefficient. USACE 1984 Shore Protection Manual (SPM) with straight, parallel depth contours.

Seeking the intersection point within the chart we obtain:

$\left(\mathrm{K}_{\mathrm{S}} \cdot \mathrm{K}_{\mathrm{R}}\right)_{\mathrm{M}}=0.88 ; \mathrm{a}_{\mathrm{M}}=23^{\circ}$

Thus the wave height at point $M$ results:

$\mathrm{H}_{\mathrm{M}}=\left(\mathrm{K}_{\mathrm{S}} \cdot \mathrm{K}_{\mathrm{R}}\right)_{\mathrm{M}} \cdot \mathrm{H}_{0}=0.88 \cdot 5.00=4.40 \mathrm{~m}$

It is clear that the propagated wave doesn't break at point $\mathrm{M}$ depth since $\mathrm{H} / \mathrm{d}<0.78$ (McCowan) at point M.

From point $M$ to point $A$ only diffraction occurs since we have assumed that depth is constant within the harbour basin. For diffraction calculations at point $A$ we will use the dimensionless Wiegel Charts from the USACE SPM. We must choose among all which best matches the propagated wave front angle, e.g. $\theta=120^{\circ}$ (best approximation to the real angle $113^{\circ}$. We could interpolate too if necessary).

$r / L_{M}=250 / 87=2.87 ; \beta=30^{\circ}$. 


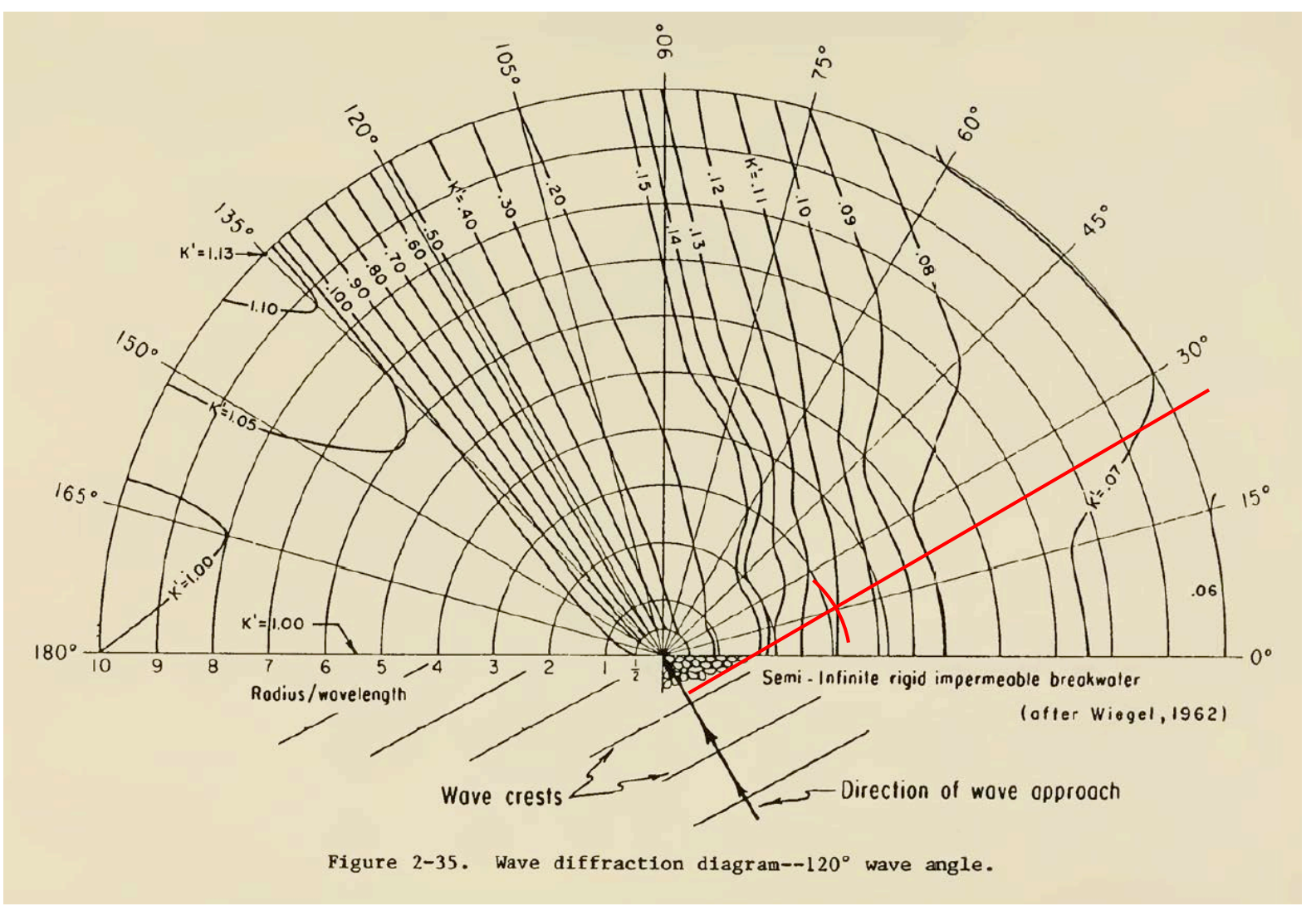

Fig. 9. Dimensionless Weigel diffraction plate. USACE SPM (1984)

Seeking the intersection point within the chart we obtain:

$\left(K_{D}\right)_{A}=0.12$

Thus the wave height at point $A$ results:

$\mathrm{H}_{\mathrm{A}}=\left(\mathrm{K}_{\mathrm{D}}\right)_{\mathrm{A}} \cdot \mathrm{H}_{\mathrm{M}}=0.12 \cdot 4.40=0.53 \mathrm{~m}$

The wave height $\mathrm{H}_{\mathrm{A}}$ will be acceptable depending on the type of vessel for which the harbour has been designed.

This simple methodology has been widely used in design by civil engineers not long time ago. It was a natural transition between the deterministic and probabilistic stages. Although this method doesn't take into account the effect of reflected waves on the breakwater or inside the basin during propagation, it gives us an excellent approximation to the expected results obtained by a numerical model (God bless the rules of thumb!).

\section{CONCLUSIONS}

To sum up, we would like to transcribe the profesor Svendsen's words [8] in the preface of his excellent book "Introduction to Nearshore Hydrodynamics":

$$
\begin{aligned}
& \text { If you want to model nature you must copy nature. } \\
& \text { If you want to copy nature you must understand nature. }
\end{aligned}
$$

These wise words synthesize this paper somehow. His quotation shows clearly the author's opinion about the blind use of advanced numerical models without a profound and previous knowledge of the physics behind the wave propagation phenomena. Intuition and common sense is another milestone for those who want to model nature effectively.

Rules of thumb are an excellent aid for students that start their learning process and of course for practitioners who want to know if their designs are safe at minimum costs. 


\section{REFERENCES}

[1] Neves M.G., Fontul S., Miguez M., Solari S., Pedocchi F., Teixeira L., Navarro-Pons M., Ramos-Amaya C., Muñoz-Perez J.J. (2015). Methodologies for teaching an engineering subject in different countries: comparison and results. INTED2015 Proc., pp. 1339-1346

[2] Lopez-García P., Navarro-Pons M., Muñoz-Perez J.J., Anfuso G. (2014). Audiovisual resources as a useful tool to improve the teaching of coastal engineering (Marine Science BSc degree). EDULEARN14 Proc., pp. 6117-6124

[3] Navarro-Pons M., Moreno L., Muñoz-Perez J.J., Anfuso G. \& Román-Sierra J. (2014). Success on increasing number of students that pass the coastal engineering subject. EDULEARN14 Proc., 4443-4448.

[4] Jigena B., de Gil A., Walliser J., Vidal J., Muñoz J.J., Pozo L., Lebrato J. (2016). Improving the learning process in the subject of Basic Maritime Training using GPS and Google Earth as useful tools. NTED2016 Proc., pp. 6161-6171

[5] Negro-Valdecantos V., Varela O. (2008) Diseño de diques rompeolas. Ed. Colegio de ICCP, Seinor n.28, 420 pp.

[6] Iribarren Cabanilles R., Nogales y Olano C. (1964) Obras Marítimas, Oleaje y Diques. Ed. Dossa, $376 \mathrm{pp}$.

[7] Muñoz-Perez, JJ (2012). Ondas regulares y su aplicación a la Ingeniería de Costas. Pub. University of Cadiz, 100pp.

[8] Ib A. Svendsen. Introduction to Nearshore Hydrodynamics. Advanced Series on Ocean Engineering-Vol. 24. World Scientific. 